\title{
The role of women in environmental education
}

\begin{abstract}
In the face of the increasing environmental problems that are destroying our planet, women are especially vulnerable to them. They have always played an essential role in ensuring the protection of fragile ecosystems, surviving natural disasters and organizing natural resources in a sustainable manner. Although women have done all this, besides knowing how to adapt to climate change, their contributions have generally been undervalued. For this reason, in this article a reflection is carried out around the gender-environment-sustainability interrelation. At the same time an environmental education that builds and reformulates the value of the diverse and the convergence between men and women, from similar but differentiated dimensions must be disclosed. All this is inserted in the natural and social environment, the connections between men and women, in social justice and in the forms of relationship with nature and with life. In this context, an approach to gender considerations inserted in the relations between society and nature that affect the quality of life of women and men is needed. Therefore, an emerging task for environmental education is to promote the formation and research of environmental problems by incorporating the category of gender.
\end{abstract}

Keywords: environmental education, woman, sustainable development, genus, environmental problems, life, international dimensions, toxics, chemicals, pathologies
Volume 2 Issue 5 - 2018

\author{
Macarena Esteban Ibáñez, Luis Vicente \\ Amador Muñoz \\ Universidad Pablo de Olavide, Spain
}

Correspondence: Macarena Esteban Ibáñez, Universidad Pablo de Olavide, Spain, Carretera de Utrera km I 4 I0I3 Sevilla, Tel +34616963638 ,

Received: August 04, 2018 | Published:September 10, 2018

\section{Introduction}

Since the mid-twentieth century, the environmental issue took on international dimensions, based on the knowledge and dissemination of problems associated with the degradation of the environment. There are many environmental problems that are making our planet sick. These, in turn, are closely related to other economic and social problems. The human being is in constant interrelation with his environment. When this one produces some damage it is that environmental problems are considered. These can come directly from nature, when man is installed in natural sites and natural processes; or, having an origin due to human or anthropic causes, that is to say, that man intervenes in the natural cycles generating a damage that, finally, turns against him. The environmental and social impacts that rise to the problems arise from many factors such as: unsustainable levels of resource consumption, insufficient technologies, inappropriate administrative practices, asymmetric policies of economic development, laws and regulations that ignore the true exposure of human beings and innumerable non-participatory political processes. The consumption patterns of all communities, both rich and poor, are associated in conjunction with critical threats to the environment such as the deterioration of human health. Most countries suffer from a series of environmental problems of varied nature, associated with various human activities, which endanger the sustainable development of the country.

It seems absurd that in the $21 \mathrm{st}$ century the fundamental determinant of health still being access to water and sanitation when the great change in the epidemiological situation of the Western world occurred precisely when it was understood that we had to invest in this. Regarding developed countries, one of the environmental factors that could have a great impact in the prevention of diseases is environmental pollution, responsible for a high number of deaths each year and, above all, chronic and acute pathologies, especially respiratory and cardiovascular. Regarding the use of pesticides, perhaps it is not a serious environmental problem but there is much to do so that they do not reach the food and are not a cause of morbidity. Among occupational risk factors, exposure to asbestos continues to kill thousands of people each year and other toxics and chemicals are responsible for a high number of cancers. That is the kind of challenge that who poses. A great effort must be made to prevent this pathologies. ${ }^{1-6}$ With the accumulation of multiple failures in the solution of environmental problems it has become clear that its enormous complexity forces the various sectors involved collaborating very closely. The governmental and academic groups are in a place of particular responsibility in this regard. A possible main solution to environmental problems is environmental education at all levels and sectors of society, productive or not. This is a fundamental tool to achieve a change in attitude and behavior in society, not only in producers but also in consumers around the world. In recent years, the relevance of environmental education as a field of theoretical and practical knowledge is clearly recognized. On the other hand, in the international sphere, the interrelation between the achievements of women and the environment have been considered more and more, since they are linked by a more generic concept of sustainable development. For this reason and as an important sector at a social level, women collective should be counted as one of the most relevant in the distribution and implementation of said environmental education. In this line, gender studies should offer greater opportunities for reflection towards environmental considerations, taking as axis the characteristics of the relations between society and nature in different cultural contexts.

\section{The woman and her relationship with the environment}

The policy documents (reports, declarations, action plans, platforms) emanating from the various international meetings have a certain global and regional impact, while reflecting the evolution of the ideas and trends that are guiding the thinking and action, both from governments and international organizations and from civil society organizations. For these reasons, in this chapter the development of the reflection on the gender-environment-sustainability interrelation is presented chronologically and analyzed. At the international level, the interrelationships between women's achievements and the environment have been increasingly considered, since they are linked by a more generic concept of "development". Taking a brief historical 
tour, in key meetings for the Environment, as was the Declaration of the United Nations Conference on the Human Environment (Stockholm, 1972) are not taken into account constantly using the concept of " man "as a generic of the human being. In the same way in the first World Conservation Strategy (IUCN / UNEP / WWF, 1980) that does not include social issues, only women are mentioned with topics related to population growth aspects and above all with rates of illiteracy. It is in 1992, with the first preparatory meeting of the Rio Summit, and under the organization of UNEP and on the initiative of the four regions of the developing world: Africa (Harare, Zimbabwe, 1989), Arab countries (Tunisia, 1990), Asia (Bangkok, 1991), Latin America and the Caribbean (Quito, 1991) when the decision is made to include in the program (not included a priori in the first draft) a section on the role played by women in the environmental themes and the different modalities acquired by their insertion in development processes.

This incorporation will bring about meetings held where different participants presented the information that was available at that time regarding the main environmental problems of each region and its effects on the female population, at the same time that they made proposals to incorporate them into the debate on the occasion of the Conference. . The work carried out culminated, before Rio, in two meetings held in Miami in 1991: World Assembly on Women and the Environment: Partners in Life and World Congress of Women for a Healthy Planet. In these contexts, analyzes of the situation of women in different countries were carried out and recommendations were made to the United Nations Conference to take decisions before them. Together with the proposals, the paradigm of current development was questioned and changes were called to ensure sustainability and a style of development focused on the needs and rights of people. The decisions taken were reflected in the Agenda 21 document on Women's Action, which constitutes an ethical framework in which measures are proposed focusing on the implementation of a democratic and participatory process, universal access to information, ethical positions and the full participation of women in equality with men, considered bases for change. In 1997, the fifth anniversary of the United Nations Conference on Environment and Development, numerous meetings were held to carry out follow-ups to verify whether the commitments made in Rio have been met, as well as the implementation of Agenda 21. In general terms, these evaluations have shown that although some progress has been made in terms of environmental protection, there are large deficit areas in the implementation processes of the actions and that changes in economic structures and policies have not led to significant progress in overcoming poverty and in achieving equity. Similarly, another of the issues still pending is the financial and technological cooperation of industrialized countries to those in development to be able to adopt actions and processes that lead to sustained development.

In this same process, the Commission on the Status of Women of the United Nations highlighted, once again, the need to incorporate the gender approach into the mainstream of development, as well as the design and implementation of environmental programs and policies, including those resulting from Agenda 21 and the Beijing Platform for Action at the national and local levels (United Nations, 1997a). In a complementary manner, the Report of the High Level Advisory Board on Sustainable Development for the 1997 reviews of the Rio commitments states that one of the requirements to achieve positive changes towards sustainable development is to promote autonomy and the mobilization of women (United Nations, 1997b). In light of the above, is not possible to specify that due to both social conditions and the development of modern society, women are still not visible in nature at present. With regard to nature, the more effectively the life cycles are maintained, as essential ecological processes, the more invisible they become. The alteration is violent and visible; balance and harmony are experienced, they are not seen. The low visibility within the framework of the instrumental rationality characteristic of modern thought, leads to a certain reification, in the sense that both nature and women are seen as objects subordinated to the interests that, in society patriarchal, define men: exploitation of resources, transformation of the natural environment, organization of life in factories and companies, access to management positions in politics and the administration of the State, and allocation of value to jobs that have place in the home and those who execute them.

As Novo (year) comments, the panorama that this behavior has left us is worrisome. Although in the North of the planet the situation has changed a lot, contemplated in general terms, it offers data that force us to reflect: of the more than 1,000 million people who live with less than a dollar a day in the world, around $70 \%$ are women, the poorest of the poor, deprived not only of access to resources derived from their economic condition, but also, in many cases, suffering double discrimination that denies them access to education (also $70 \%$ of illiterates of the world are women) and decisions in the community, based on their feminine condition (Novo, 2003). This little visibility and in some moments invisibility, are products of the patriarchal culture. In this line Habermas (1984) states that the consideration of nature as a subject, as a "fraternal nature", requires seeing "others" (also women) equally in their capacity as subjects, that is, give them visibility. Therefore, it is necessary to move towards an environmental education that builds and reshapes the value of the diverse, of the multicultural wealth, of the convergence between men and women, exponents and builders of life, from similar and differentiated dimensions. In the very concept of the environment, of the relations between society and nature, are immersed the urgencies of harmonious nexus within society, in the connections between men and women, in social justice, in the forms of relationship with nature and with life. Environmental education towards a sustainable future must go a long way, in order to make explicit gender considerations in its training processes. This requires a better understanding of the social and cultural situations that condition the management of the environment and are part of the options of real development. A more explicit approach is needed to the gender considerations inserted in the relations between society and nature that have a favorable or unfavorable impact on the quality of life of women and men. And a new approach to social analysis is necessary in reference to participatory options for local or regional environmental management

\section{Environmental education as an instrument of social integration}

In view of the above, it is possible to argue that the dilemma of exploiting natural resources or keeping them untouchable has passed, for more than half a century to date, from an almost theoretical discussion to a serious confrontation of views on the way of life of current and future generations. The progressive urbanization caused by the accelerated concentration of the population and the modifications in the policies related to the countryside have resulted in drastic changes in the environment. Because of this, we can see that with the growing demand for agricultural, livestock, forestry, mining and energy products it is undeniable that the main source of environmental 
problems is found in human behavior. The lack of information, awareness and capacity are the main causes of the inadequate social response. In order to adequately assess the above, it is fair to point out that the environmental crisis is not a modern problem; the new ones are its dimensions. To this it should be noted that technology promotes the accelerated degradation of the environment and natural resources when it is not used rationally and that the response capacity aimed at its restoration is in the long term. To speak of sustainability in development implies being fully aware that refer precisely to a relationship of conflict between society and nature; relationship that should aim at a harmonious coexistence, which tends to guarantee an adequate level of human life, which seeks to avoid the deterioration of ecosystems and obtain the greatest possible balance of them.

Every day it is pointed out that conservation and development have rarely been combined and often seem incompatible, and will be so in the measure that no sustained development has been foreseen. Under this perspective, it is important to consider that social welfare is based on the use of natural resources and the modification of the biosphere, according to the use of human and financial resources, in such a way that the satisfaction of the needs and the standard of living they depend directly on the development model that is adopted. It is clear then that the development model that has been applied is harmful to natural resources, which together with the environment have been subjected to a pressure and rate of consumption greater than its capacity for regeneration. It becomes necessary, then, to start from different bases that contemplate as goals not only the welfare of the current generations, but to foresee the healthy subsistence of future generations. Therefore, the model of socioeconomic development that is required is a sustainable development model, in which it is fundamental that the use of natural resources be rational and potentially sustainable (and sustained). In this sense, a "new ecological culture" manifests itself, which is evident at all levels and sectors. While in the government a growing process of organization is perceived, in the civil society the claim, the denunciation and the management increase as participative expressions. Further, the creation of official dependencies, such as the constant manifestation of non-governmental organizations, political events, scientific events, etc, may be observed.

The relevance of Environmental Education as a field of theoretical and practical knowledge is clearly recognized, at present, considering the economic, political, social and cultural variables that allow to explain the diverse situations that manifest themselves in the environment, enabling to speak about "environmental problems", as well as the need to arrange some measure to face it. Actually, it is expected that Environmental Education will be able to arouse changes in the mentalities, attitudes, knowledge, behavior, etc. Also, people and societies must have, increasingly restless due to the need to combine daily life with the giant technological, economic, cultural, environmental changes in which modernity is expressed: with the effects and consequences that are occurring in the current, developed and undeveloped societies, and in their citizenship. This belief supposes a direct interpretation of the role of Social Pedagogy in the understanding of the environment: what can Social Education do as a practice and as a profession in favor of the environment?

The White Paper for Education (1999) in Spain echoes these changes. Among them appears the growth and sustainable development and protection of the environment, without forgetting all that it collects, including attention to diversity and exclusion; internalization, economic and socio-economic globalization and the need for "local" response and attention to the services to the citizenship that this demands; the new international framework that involves contact and exchange between collectives, citizens with diverse identities. Demand for a new culture of interculturality, mediation and coexistence. All this translates into a new type of society, the knowledge society. It shows two key educational profiles: dynamic learning and lifelong learning linked in a transversal way to the incorporation and use of new information, communication technologies, critical and responsible participation to react to transformations and the imbalances that the new situation produces. From here, it exposes actions, plans, programs and projects that from an educational vision would be related and linked to continuous actions, where the involvement of the education professional and the participants is absolutely fundamental, such as Programs, actions, projects and initiatives linked to daily life; Programs, actions, projects and initiatives linked to improving the quality of life; Programs, actions, projects and cultural and leisure initiatives, and Programs, actions, projects and initiatives linked to the environment.

It is in this field where the importance of the role of education that must transcend the areas of regulated, formal, school education, reach the framework of socio-educational development of individuals and groups in the context of non-formal, non-formal education. It is here where Social Education appears, from the academic and professional side, responding to social and citizenship demands and, of course, the imbalances that come with these transformations. In this area and under these criteria is where the relationship is valued, the link between two realities that take place, sometimes parallel over time and end up sharing criteria, purposes, commitments, etc. As echoed by Caride and Meira (2007), both are developed definitively in the period of the welfare state, in order to respond to the commitments posed by the new social imbalances of the transformations of the moment. In one case, as a consequence of the imbalances emanating, as a result (given the results) of industrial excesses and the problems posed by the socioeconomic model. In the other, alarmed by the social dysfunction it causes; being here as previously mentioned, where education ends up echoing and trying to give an answer. Sharing both the global crisis and the necessary security before the quality of life and the uncertainty that, in any case, the current society entails. Initial educational approaches arise in the context of training in values that facilitate respect for nature where people perform actions. To this approach in a reductionist principle (didactic of ecology), another more inter or multidisciplinary one takes place that gives more importance to the social and cultural nature of the environment.

It is necessary to understand the environment as a set of representations, interrelated and complementary dimensions, that educationally should be conceived as a social and community project. Where the educational activities are developed; at the same time, with the commitment that should be the axis that guides them, participation, community development, etc. must be encouraged. (Sauvé, 2006) This seeks to ensure the means to lead a correct and adequate community life, where education, including environmental education should not be understood as problem solving or modification of civic behavior.

\section{Need for a change in attitudes and values: gender and environmental education}

A positive environmental ethic, constituted by a series of values and behaviors that help to preserve the ecological integrity of the Earth, as stated by Caduto (1985) must be an integral part of every 
person. Cultural beliefs play an important role when determining student attitudes towards the environment. The assimilation of environmental values will be more effective if they are taught at an early age and if they are based on a solid system of general moral values because they will become part of the subject's own morality. The current problems of excess population, overconsumption, high technology and scarcity of associated resources, as well as the alteration of the environment make it very difficult to trace an ideal moral course. As people become aware of the intimate relationship between man and, of course, women and the environment, and the fact that all persons depend on it, it is possible to realize that any attack on the environment often involves violation of our health or welfare of another person or country. Faced with this reality, it is important to advocate that the human being, man and woman, although playing different roles imposed by society; There should be no difference in aspects related to the defense of the environment in which they are developed. Therefore, both must work under the same purpose but at different levels and with different activities with the environment, however, the most important thing is for both to become aware of the pressing nature of environmental problems.

The decision to participate in the improvement of environmental quality cannot be stimulated only from the cognitive sphere. It depends above all on personal motivation and a sense of responsibility that results from the development of a personal environmental ethic. Thus, the formation of autonomous and morally qualified persons in the development of social and environmental values hould be seen as affirmed by. If environmental is understood such as extension and education processes are a set of activities that promote an equitable and harmonious relationship between human beings and nature, it is recognized and understood how equity works between human beings, between men and women- (Sancho, 2012) In this sense, environmental education is not a field of study, such as biology or ecology. It is a process that must integrate multiple approaches such as gender, diversity of opinions and beliefs among others. All these factors favor the sustained adoption of behaviors that lead men and women to live their lives better, to manufacture their products, buy their material goods and develop technologically in a way that minimizes the degradation of the original landscape, pollution of air, water or soil, and threats to the survival of flora and fauna. Precisely because environmental education is a method to continue development while protecting, preserving and conserving the life support systems of the planet (Smith-Sebasto, 1997), it is essential to link the theme of gender and the proposals that it contains. They must be seen as an integrated whole, because if any of these three important factors fail it is not likely that true Sustainable Development will be achieved.

Sosa et al., ${ }^{7,8}$ assumes that the main objective of the environmental education should be the "generation of attitudes" in favor of the environment. The EA has to commit, then, in the formation of an "ecological conscience" that has to be understood as "moral conscience", for what will be constituted in Moral Education. For this reason, it considers that the Environmental Education Programs must be constructed with a global, holistic vision that includes: people's attitudes towards others; people's attitudes towards society; the attitudes of people towards the natural environment. Brundtland (1987) expresses this line when he states that the environment does not exist as a separate sphere from human actions and needs. Attempts to defend it in isolation from human concerns have meant that the term environment acquires a connotation of naivety in some political circles. Going deeper into the topic of attitudes towards others and towards society in general, occurs an introduction in the broad field of Human Rights, because the Universal Declaration of Human Rights forms the set of norms with the most consensus in the History of Humanity. Specifically, in the field of Environmental Education, it is specified that everyone has the right to an adequate standard of living that ensures, as well as to his family, health and well-being, and especially food, clothing, housing, medical care and social services necessary. Is therefore essential other values, such as solidarity and cooperation that are increasingly defended in these human rights.

Calixto $^{9,10}$ argues that the role of women as educators in the family includes the environment, around the environment shows personal concern for involving family members in energy saving activities, healthier eating practices and greater coexistence. Without ceasing to fulfill the role of at home and mother of a family. Therefore, issues such as the environmental role of women in the home and how it is assumed by the other members of the family in specific environmental activities, emerge as interesting objects for research, as the results emanated from it could favor the implementation of environmental policies in this regard. It cannot be forgotten that the fight against poverty is considered one of the most immediate lines of action on a global scale, a preferred objective agreed upon by the entire community and by international organizations, which agree that this issue is one of the essential issues for the rebalancing of our societies in terms of equity. ${ }^{11-15}$ It is not possible to ignore that hunger and poverty are the consequence of environmental imbalances (ecological and social) but that they are also the root of a very significant part of the problems of our environment. For this reason, it is important to emphasize that if education is aimed at the integral development of the person, it cannot do without the values that comprise Human Rights for various reasons, among them because they make up the "consensus ethic" that governs coexistence among people, as well as because they constitute the foundations of a democratic culture based on the essential ethical values: freedom, dialogue and participation. Other reasons are because they constitute the principles of an educational conception that, fundamental, guides the curriculum and the teaching task; and because they serve as integrating elements of a broad conception of education for peace and allow us to approach the global problem through the so-called transversal axes, while introducing us to the new knowledge that comes from the world of science and the technology.

In short, it is possible to recognize that human rights are the foundation of human coexistence and that they should be used to educate morally without forgetting that they not only have an ethical dimension, but also philosophical, social and legal. According to the text published by the Ministry of Education and Science of the Junta de Andalucía (1989) on the occasion of the 50th anniversary of the Declaration of Human Rights, Education for Peace, Human Rights and democracy are currently considered, both regional as well as international scale not only as a need for societies to face changes and seek alternatives to global problems, but as the essential purpose of the right to education. For this reason, education for peace is defined as explained by Tuvilla (1990) as a process aimed at both individuals (both men and women) and society, so that they act, in accordance with the principles contained in the Universal Declaration of Human Rights and the entire international legal body that develops them, in favor of Development Sustained of the peoples, the protection and conservation of the environment, the aspiration and action in favor of disarmament, the strengthening of social coexistence and the non-violent solution of conflicts. The previous definition is based on a positive conception of peace as the situation characterized by a reduced level of violence and a high level of justice, understood the 
latter as the satisfaction of basic human needs through a Sustainable Environmental Development. A modern approach to the problems related to education for peace, human rights and democracy is currently included in the Integrated Action Plan emerging from the 1994 International Conference on Education. This Plan identifies the aims of education, action strategies, policies and guidelines at the institutional level. In the sixth section of said Plan, it is stated that education must teach citizens to respect cultural heritage, to protect the environment and to adopt production methods and consumption patterns that lead to sustainable development. The harmony between individual and collective values and between immediate basic needs and long-term interests is also indispensable. ${ }^{15-26}$

\section{Final considerations}

The search for a sustainable society is not possible without specifying a series of behavioral patterns of the subjects with respect to the environment. So that the positive actions aimed at achieving a balance between the quality of life / quality of the environment and the responsible ecological behavior should be the purpose of Environmental Education. It is important to emphasize that these behavior patterns are intended to educate people in favor of the environment, but with the intention that they are part of an informed and accepted action. That is why the coordinated work between knowledge and environmental attitudes is so important. In order to achieve a change in personal behavior in relation to the Environment, it is not only necessary to replace one behavior with another, but the achievement of a continuous action through the management of personal strategies. When acting consciously and motivated in favor of the improvement of the Environment, one behavior can lead to the practice of another similar one. The preparation of the subject for action implies that each one is informed about environmental issues and has a positive attitude towards the environment. But even seeing these necessary conditions, they are not enough for solving environmental problems. For people to be able to act, they need to know a variety of action skills to solve them.

In view of the foregoing, it is increasingly important to endow environmental education with a gender perspective. For this mainly, as in the educational field, in general, environmental education should have to try to incorporate concepts and new methodologies, that make it possible to explain the new relationships and the links that are evident and that therefore demand an interdisciplinary work. In this sense it is also necessary to broaden the role of women as educators to those of environmental educators, since they are who will be able to better involve family members in energy saving activities, healthier food practices and greater coexistence. In this way, the presence of new observable objects becomes evident, which represents a new challenge to investigate environmental education from a gender perspective and then be able to describe the relationship: woman-man and the environment. The development of environmental education on a day-to-day basis must be seen as a continuous questioning of the ways in which social relations develop, on the representations that are made about the environment and on the role assumed in everyday reality. Environmental education is interested not only in explaining the natural environment, but also in the social and the built environment, in which the different responsibilities of the different social sectors in the environment are clearly manifested. As well as the diverse relationships that occur between the genres. An emerging task for environmental education is to promote the formation and research of environmental problems by incorporating the category of gender.
Gender equity aims for men and women to develop their capacities, potentials, roles, as well as access to resources, and the administration of the environment on equal terms. And today's demand, turned into a claim, is for women to have genuine participation and representation in the decision-making process both at the level of their community, their country, and internationally.

\section{Acknowledgements}

None.

\section{Conflict of interest}

The author declares there is no conflict of interest.

\section{References}

1. Amador, Esteban, Rocío Cárdenas, y Teresa Terrón. Ámbitos de profesionalización del educador/a social: perspectivas y complejidad. Revista Humanidades, 2014. p. 21.

2. Amador, Macarena Esteban y Victoria Pérez. La educación ambiental y la educación de personas adultas y mayores. Participación social y voluntariado ambiental. Madrid: CONAMA. 2012.

3. Amador L. y Esteban, M y Rocío Cárdenas. La Educación Medioambiental en Personas Adultas y Mayores en el contexto de la Educación Social. En La Pedagogía Social en la Universidad. Investigación, Formación y Compromiso eds Sonia Morales Calvo, Juan Lirio Castro, Rosa María María Ytarte. 2012;673-686

4. Amador L, y Esteban M. Desde la educación social a la educación ambiental: hacia una intervención educativa socioambiental. Revista Humanidades. 2011. p. 18.

5. Esteban, M y Amador L. Attitudes of University Students towards the Environment: Environmental Education and Innovation Revista Humanidades, 2017. p. 31.

6. Esteban M, Moreno, O y Amador L. Educación ambiental y diversidad cultural como ejes para la transmisión de valores socioambientales en un contexto educativo en Identidades culturales y educación en la sociedad mundial. González, editor. J.C. Huelva: Universidad de Huelva. 2012.

7. Sosa NM. Educación Ambiental: sujeto, entorno y sistema. Salamanca: Amarú. 1989.

8. Sosa NM. Educación Ambiental, Ética, Ecología y Universidad, Comunidad Educativa. 1994;213:6-10.

9. Calixto R. El papel y la percepción ambiental de las educadoras, informe de investigación. México: UPN. 1997.

10. Agencia Europea de Medio Ambiente. Medio Ambiente en Europa. Informe Dobis. Luxemburgo: Oficina de Publicaciones Oficiales de la Comunidad Europea, 1998.

11. Altafaj A. Cumbre Mundial sobre Desarrollo Sostenible en Johannesburgo: nueve días para decidir qué planeta heredará las generaciones futuras, Diario $A B C, 2002 ; 154: 3-7$.

12. Benayas del Álamo P. Concepto y fundamentos de la Educación Ambiental: Historia y antecedentes, Málaga: Artigraf.

13. Caduto M. Guía para la enseñanza de valores ambientales. UNESCO: IPEE. 1985.

14. Caride J, A y Meira PA. Educación Ambiental y desarrollo humano. Barcelona: Ariel Educación. 2001.

15. Consejería de Educación y Ciencia. Derechos Humanos. 50 aniversario de la Declaración de los Derechos Humanos. Sevilla: Junta de Andalucía. 1998. 
16. Moreno O. Educación Ambiental y Educación para la Ciudadanía desde la Perspectiva Planetaria. Estudio de Experiencias Educativas en Andalucía. Pedagogía Social Revista Interuniversitaria. 2014;23:278-279.

17. Novo M. La mujer como sujeto, ¿utopía o realidad? Revista Polis, 2003;2(6).

18. Novo M. Mujer y medio ambiente: los caminos de la visibilidad. Utopías, educación y nuevo paradigma Madrid: Los Libros de la Catarata. 2007. p. 248.

19. Pascual, M y Herrero, Yayo. Ecofeminismo, una Propuesta para repensar el Presente y construir el Futuro. En Mujeres y ecología: historia, pensamiento y sociedad eds Puleo, A. Segura, C. y Cavana, M.L. Madrid: Laya. 2010.

20. Puyol R, Cano L. Nuevas tendencias en investigaciones en Educación Ambiental. Madrid: Organismo Autónomo de Parques Naturales Ministerio de Medio Ambiente. 2007.
21. Rodríguez M. Integración de la Educación Social y la Educación Ambiental. Artículo publicado en la Revista Global Hoy, 2006. p. 8.

22. Sachs A. Ecojusticia. La unión de los Derechos Humanos y el Medio Ambiente. Bilbao: Bakeaz. 1996.

23. Sancho L. La educación ambiental, la extensión y la perspectiva del género: para enriquecer las propuestas metodológicas. Revista Forestal Centroamericana. 2012. p. 38-41.

24. Sáez J. Pedagogía Social y Educación Social. Historia, Profesión y Competencias. Madrid: Pearson. 2007.

25. UNESCO. Una educación para el segundo milenio. París: UNESCO. 1997.

26. VV AA. Pedagogía Social. Revista Interuniversitaria. "Educación Ambiental, desarrollo y cambio social" Madrid: SIPSS. 1998. 